\title{
A Facile and Efficient Method for Catalytic Acetylation of Alcohols with Acetic Acid
}

\author{
Anindita Dewan, ${ }^{\dagger}$ Utpal Bora, ${ }^{*}$ and Dilip Kumar Kakati ${ }^{\dagger+*}$ \\ Department of Chemistry, Dibrugarh University, Dibrugarh 786004, Assam, India. *E-mail: utbora@yahoo.co.in \\ ${ }^{\dagger}$ Department of Chemistry, Gauhati University, Guwahati 781014, Assam, India. *E-mail: dilip_kakati2003@yahoo.co.in \\ Received July 29, 2010, Accepted September 19, 2010
}

Key Words: Acetylation, Alcohols, Solvent free, Cetyltrimethylammonium ferricyanide

Protection of alcohol as corresponding acetate ester is one of the most fundamental and widely used strategies in contemporary organic chemistry. ${ }^{1}$ Usually acetyl chloride and acetic anhydride are employed as the acylating agents in the presence of a convenient acidic or basic catalyst. ${ }^{2}$ However, both the reagents are corrosive and lachrymator and involve the use of tertiary amines such triethylamine, pyridine and DMAP and therefore are not always ideal. Several catalytic systems involving Lewis acids ${ }^{3-7}$ and metal triflates ${ }^{8-13}$ have been explored for the esterification of alcohols using acetic anhydride. Recently acetic acid, which is the precursor of acetic anhydride, was used as acylating agent in presence of ferric perchlorate, ${ }^{14}$ however perchlorates are potentially explosive. Therefore, development of simple and environmentally friendly method for acetylation of alcohols utilizing inexpensive and readily available reagent is still desirable. Among the various transition metals, iron is one of the most abundant metals on the earth, and one of the most inexpensive and environmentally friendly ones. Therefore recently iron based catalyst and reagents are frequently used to address economic and ecological challenges in various organic transformations. ${ }^{15}$ Among the various reagents used in organic transformations, phase transfer reagents attract attention due to its unique features and potentiality in organic synthesis. These reagents have amphiphilic cations (mostly quaternary ammonium ions) as carriers of the catalyst unit to solubilize it in the reaction medium. Moreover, these types of phase-transfer reagents are also able to catalyze organic transformations, ${ }^{16}$ but to the best of our knowledge the utilization of these types of reagents as catalyst are rarely exploited in single phase reaction. In this communication we wish to report the use of easily accessible and inexpensive cetyltrimethylammonium ferricyanide $(\mathrm{CTAFeCN})^{17}$ as a useful catalyst in acetylation various hydroxyl groups.

Initially to establish the catalytic activity of CTAFeCN in esterification reaction, we carried out a series of reactions using 1 -octanol as model substrate. In a typical procedure, to a solution of the alcohol ( $1 \mathrm{mmol})$ and CTAFeCN $(0.05 \mathrm{mmol})$, acetic acid $(3 \mathrm{~mL})$ was added and the reaction mixture was stirred at room temperature for $24 \mathrm{~h}$. It was found that at room temperature the reaction did not proceed and substantial amount of 1-octanol was recovered from the reaction mixture (Table 1 , entry 1). However, increase of the reaction temperature to $60{ }^{\circ} \mathrm{C}$ led to completion of reaction within $5 \mathrm{~h}$ (vide TLC) with $85 \%$ isolated yield (entry 2). Interestingly, increase of the reaction temperature up to $80^{\circ} \mathrm{C}$, resulted in the complete reaction within
Table 1. Acetylation of 1-octanol under different conditions

\begin{tabular}{ccccc} 
Entry & $\begin{array}{c}\mathrm{CTAFeCN} \\
(\mathrm{mmol})\end{array}$ & $\begin{array}{c}\text { Temperature } \\
\left({ }^{\circ} \mathrm{C}\right)\end{array}$ & $\begin{array}{c}\text { Time } \\
(\mathrm{h})\end{array}$ & $\begin{array}{c}\text { Yield } \\
(\%)\end{array}$ \\
\hline 1 & 0.05 & $\mathrm{Ct}$ & 24 & - \\
2 & 0.05 & 60 & 5 & 85 \\
3 & 0.05 & 80 & 1 & 95 \\
4 & $\mathrm{CTAF}$ & 80 & 2 & - \\
5 & 0.025 & 80 & 2 & 60 \\
\hline
\end{tabular}

Yield refers to isolated pure acetate

$1 \mathrm{~h}$ with $95 \%$ yield (entry 3 ). But the acetylation reaction did not proceed at all in absence of CTAFeCN (entry 4) and use of $0.025 \mathrm{mmol}$ of catalyst led to dramatic decrease in isolated yields (entry 5). Fe (III) reagents are usually known for its strong oxidizing property. ${ }^{18}$ But due to low oxidation potential of some ferric complexes, they were unable to oxidize alcohol ${ }^{19}$ to the corresponding carbonyl compounds. In this acetylation reaction, the exact role of CTAFeCN has not been understood at this point, it may activate the acyl moiety by coordination, prompting the acetylation process.

To evaluate the scope and limitations of the current procedure, reactions of a wide array of electronically and structurally diverse alcohols were exposed to the above reaction conditions. The results were depicted in the Table 2. The effectiveness of the current method is evident from the fact that the variety hydroxy compounds including allylic, secondary, cyclic, aromatic, and benzylic were acetylated in high yield under the reaction conditions (entry 2-12). Dihydroxy compounds, such ethylene glycol could also be acetylated in high yield under the aforesaid reaction conditions (entry 9). Current method is also feasible for the acetylation of steroidal hydroxy group in high yield (entry 12). However this methodology is not compatible with tertiary alcohol. Use of substituted acetic acid e.g. trichloroacetic acid also led to the formation of corresponding acetate in good yields (entry 13-16). The sensitive functional groups such as bromo, double bonds, and triple bonds remained unaffected under the current reaction conditions.

In conclusion, we have developed a simple iron based catalyst for acetylation of alcohols and phenols using inexpensive and readily available acetic acid as acetylating agent in base free 
Table 2. Acetylation of alcohols with acetic acid catalyzed by CTAFeCN

$$
\overbrace{\mathrm{R}^{\prime \prime}}^{\mathrm{OH}}+\underset{\mathrm{R}=\mathrm{CH}_{3}, \mathrm{CCl}_{3}}{\mathrm{C}_{\mathrm{OH}}} \frac{\mathrm{CTAFeCN}}{80^{\circ} \mathrm{C}} \underset{\mathrm{R}^{\prime \prime}}{\mathrm{R}^{\prime}}>-\mathrm{O}
$$

(c)

All the products were characterized by ${ }^{1} \mathrm{H}$ NMR, IR, and Mass spectra. Yield refers to pure isolated yield.

conditions. The reaction is unique in using a phase transfer reagent as a catalyst in a single phase reaction.

\section{Experimental}

General procedure for acetylation. To a stirred solution of 1-octanol (1 mmol) in acetic acid $(3 \mathrm{~mL}), \mathrm{CTAFeCN}(0.05$ mmol) was added and heated at $80{ }^{\circ} \mathrm{C}$ for appropriate time
(TLC). After completion, the reaction mixture was allowed to cool to room temperature and diluted with ether $(30 \mathrm{~mL})$. The reaction mixture was filtered through celite pad and the filtrate washed with brine $(3 \times 20 \mathrm{~mL})$. The organic phase was dried $\left(\mathrm{Na}_{2} \mathrm{SO}_{4}\right)$ and concentrated under reduced pressure. The residue was chromatographed (silica gel, ethyl acetate: $n$-hexane $=1: 10$ ) to give the pure acetate (95\% yield). IR $(\mathrm{KBr}) \mathrm{cm}^{-1} 1238.9$, 1743.5. ${ }^{1} \mathrm{H}-\mathrm{NMR}\left(400 \mathrm{MHz}\right.$ in $\left.\mathrm{CDCl}_{3}\right) \delta 0.87(\mathrm{t}, J=6.8 \mathrm{~Hz}, 3 \mathrm{H})$, $1.23-1.32(\mathrm{~m}, 10 \mathrm{H}), 1.57-1.69(\mathrm{~m}, 2 \mathrm{H}), 2.08(\mathrm{~s}, 3 \mathrm{H}), 4.08(\mathrm{t}, J=$ $6.8 \mathrm{~Hz}, 2 \mathrm{H})$.

\section{References and Notes}

1. Green, T. W.; Wuts, P. G. M. Protective Groups in Organic Synthesis, 3rd ed.; John Wiley and Sons: New York, 1999; p 150.

2. (a) Horton, D. Organic Synthesis Collective; Wiley: New York, 1991; Vol. V, pp 1-6. (b) Rana, S. S.; Barlow, J. J.; Matta, K. L. Tetrahedron Lett. 1981, 22, 5007. (c) Monrsit, A. A.; Pujol, H.; Poupat, C.; Ahond, A.; Potier, P. Tetrahedron Lett. 1996, 37, 9189. (d) Takeda, K.; Nakajima, A.; Yoshii, E. Synlett 1977, 255.

3. Chandrasekhar, S.; Roma Chander, T.; Takhi, M. Tetrahedron Lett. 1998, 39, 3263.

4. Iqbal, J.; Srivastava, R. R. J. Org. Chem. 1992, 57, 2001

5. Backer, R. H.; Bordwell, F. G. Org. Synth. 1955, 3, 141.

6. Miyashita, M.; Shiina, I.; Miyoshi, S.; Mukaiyama, T. Bull. Chem. Soc. Jpn. 1993, 66, 1516.

7. Kumareswaran, R.; Gupta, A.; Vankar, Y. D. Synth. Commun. 1997, 27, 277.

8. (a) Barret, A. G. M.; Braddock, D. C. Chem. Commun. 1997, 351. (b) Hanamoto, T.; Sugimoto, Y.; Yakoyama, Y.; Inanaga, J. J. Org. Chem. 1996, 61, 4491.

9. Ishihara, K.; Kubota, M.; Kurihara, H.; Yamamoto, H. J. Org. Chem. 1996, 61, 4560 .

10. (a) Orita, A.; Tanahashi, C.; Kakuda, A.; Otera, J. Angew. Chem., Int. Ed. 2000, 39, 2877. (b) Orita, A.; Tanahashi, C.; Kakuda, A; Otera, J. J. Org. Chem. 2001, 66, 8926.

11. Chandra, K. L.; Saravanan, P.; Singh, R. K.; Sing, V. K. Tetrahedron 2002, 58, 1369.

12. Karimi, B.; Maleki, J. J. Org. Chem. 2003, 68, 4951.

13. Chauhan, K. K.; Frost, C. G.; Love, I.; Waite, D. Synlett 1999, 1743.

14. Heravi, M. M.; Behbahani, F. K.; Shoar, R. H.; Oskooie, H. A. Cat. Commun. 2006, 136

15. (a) Bolm, C.; Legros, J.; Le Paih, J.; Zani, L. Chem. Rev. 2004, 104, 6217. (b) Enthaler, S.; Junge, K.; Beller, M. Angew. Chem. Int. Ed. 2008, 47, 3317. (c) Bauer, E. B. Curr. Org. Chem. 2008, 12,1341

16. Mishra, B. K.; Kuanar, M.; Sharma, A.; Nayak, B. B. Indian Journal of Chemistry 2001, 40B, 724.

17. To a stirred solution of cetyltrimethylammonium chloride ( $3 \mathrm{mmol})$ in water $(50 \mathrm{~mL})$ was slowly added aqueous solution of $\mathrm{K}_{3}[\mathrm{Fe}$ $\left.(\mathrm{CN})_{6}\right](1 \mathrm{mmol}, 10 \mathrm{~mL})$ at room temperature. The mixture was stirred continuously until yellow solids were formed. The resulting reaction mixture was filtered off and washed with water and dried under vacuum to afford cetyltrimethylammonium ferricyanide (71\% yield based on $\left.\mathrm{K}_{3}\left[\mathrm{Fe}(\mathrm{CN})_{6}\right]\right)$. IR $(\mathrm{KBr}) \mathrm{cm}^{-1} 2920.4,2114.4$, 1465.1. ${ }^{1} \mathrm{H}-\mathrm{NMR}\left(400 \mathrm{MHz}\right.$ in $\left.\mathrm{CDCl}_{3}\right) \delta 0.80(\mathrm{t}, J=4.2 \mathrm{~Hz}, 9 \mathrm{H})$, $1.13-1.25(\mathrm{~m}, 78 \mathrm{H}), 2.50(\mathrm{t}, J=6.2 \mathrm{~Hz}, 6 \mathrm{H}), 3.20-3.34(\mathrm{~m}, 33 \mathrm{H})$. Elemental analysis: Calculated: $\mathrm{C}, 71.30 \% ; \mathrm{H}, 11.80 \% ; \mathrm{N}, 11.80 \%$ Found: C, $70.80 \%$; H, $12.00 \%$; N $11.50 \%$.

18. (a) Heravi, M. M.; Ajami, D.; Ghassemzadeh, M. Chem. Commun. 1999, 833. (b) Heravi, M. M.; Ajami, D.; Mojtahedi, M. M.; Ghassemzadeh, M. Tetrahedron Lett. 1999, 40, 561.

19. Kotani, E.; Kobayashi, S.; Ishii, S.; Tobinaga, S. Chem. Pharm. Bull. 1984, 32, 4281. 